\title{
Discussions on Problems in Mainstream Ideological Education in Universities and Strategies Therefore
}

\author{
Weiwei Guo \\ College of Marxism, Taishan University, Tai'an Shandong, 271000, China
}

Key words: Universities, Mainstream ideological education, College students, Internet Age, Cultural shock.

\begin{abstract}
In the new era when diversification development is focused on and Internet technology is taken as the core, people enjoy wider channels to acquire knowledge and information, which greatly influences the political value orientation of young students, and brings unprecedented severe challenges to the mainstream ideological education of universities. Universities must clearly position themselves, define the development direction of mainstream ideological education, expect the impacts of multi-culture, identify problems, promote the beneficial and abolish the harmful, establish a set of stable and effective mainstream ideological education system, and indicate the direction for students to set proper world view, outlook on life, and value.
\end{abstract}

\section{Introduction}

The General Office of the CPC Central Committee and the General Office of the State Council jointly printed and distributed the Opinions on further Strengthening and Improving the Propaganda Ideology Work of Universities in the New Situation, explicitly providing that the mainstream ideological and public opinions of universities should be constantly enhanced to strengthen ideological education. Ideological education is an important way to spread the ideological and political education of the state and shape the talents needed in future development, and the political guarantee for the training of high-quality scientific and technological talents. Hence, universities should actively and initiatively play a correct guiding role in mainstream ideological education, to cultivate qualified socialism successors who serve the public well and adapt themselves to the trend of development of the new era.

\section{Connotation of Mainstream Ideological Education of Universities in the Contemporary Era}

There are multiple social groups holding different ideologies in society, whose economic forms and political statuses are different, and performances reflect different ideological schools because of large differences in theory and viewpoint. From the aspect of development trend, some schools blend into each other, while others stand opposite, all of which together form the huge complex social spiritual network in nowadays society.

Holding a significant position in ideological construction, universities are the culture base serving the superstructure. It is universities that train and educate talents, promote social, political and economic development, and reflect the passion and decision of constantly pursue progress of a country. Thus, the mainstream ideological education of universities is an epitome of social development, and the ideas and concept forms reflected thereby permeate into various fields of social life little by little from here, to form a common view similar to social system to be observed and fulfilled. Presently, the basic task of mainstream ideological education is to convert the theory of Marxism ideology into political conviction of the public, establish its guiding position, uphold the socialist road and adhere to the leadership of the CCP, which is exactly the essential connotation of mainstream ideological education of universities.

Education is always an important part of the superstructure of a country, which assumes the responsibilities of training and transporting talents to society, innovating and spreading knowledge, 
and providing services to society because of its class character. Carrying mainstream ideological education in universities, on one hand, can raise students' ideological and political quality and facilitate changing the future and fate of a country, and on the other hand, can help students set proper scientific world view, value and view of life, and make students adhere more closely to collectivism and the spirit of patriotism. The product of mainstream ideological education is ability and also a kind of spiritual shackles.

Under the context of information networking, college students' cognitive style and action fashion are greatly changing, and the traditional mode of mainstream ideological education of college students is facing a more complex situation and more severe challenges. In the new situation of mainstream ideological education of college students, the traditional methods and mode will not work anymore, and breakthroughs and innovations must be made, so that we can adapt to the constantly changing requirements of the era. ${ }^{[1]}$

\section{Mainstream Ideological Identity of College Students}

Universities offer ideological and political education to enhance the attraction and cohesion of mainstream ideology to students, improve students' sensitivity to and ability of distinguishing multi-culture, and help students set political concentration and political identification, which is of far-reaching significance to the establishment of students' world outlook, vie of life and value.

Universities in somewhere made a survey on college students' attention to mainstream ideological education, and the results show that most college students pay little attention to mainstream ideological education. This suggests that Chinese universities should make greater efforts to carry out mainstream ideological education, and don't have a proper knowledge thereof. From the perspective of politics and ideology, mainstream ideological education is the fundamental for the flourishing and thriving of Chinese nation in future. Thus, educators of universities should not treat mainstream ideological education as a simple concept or just glance off it, but emphasize the practical significance and effect of mainstream ideological education in college students' life and practice while stressing the education of its theories and perspectives. Therefore, mainstream ideological education of universities also can be regarded as a tie between moral education and actual life of college students. Educators should emphasize the design and integration of educational resources, and college students should learn, grasp and master it consciously and effectively.

\section{Problems in Mainstream Ideological Education of Universities}

Ideology represents the sum of specific social consciousnesses of a specific class, is the concept form of the superstructure of a society, and relates to the subjective emotion, concepts and presentations representing the fundamental interests of social classes. It covers legal thoughts, political morality, and social philosophy ideas and consciousnesses, in abundant and various forms. In contemporary China, the mainstream ideology refers to the mapping of the political system and ideology serving the socialist economy with Chinese characteristics and guided by the Marxism. In contemporary China which is experiencing political and economic reforms, people hold different viewpoints on the mainstream ideology. Especially in universities, mainstream ideological education faces more problems and challenges. Hence, universities should face up to the real problems in the education process, and seek solutions.

\section{Impact of Economic Globalization}

We are in an era of economic globalization, and face unprecedented political, economic and cultural impacts due to the rapid comprehensive development of the world. The mainstream ideological education of universities is also greatly influenced, which is reflected by the pan-cultural dissemination form. The rapid comprehensive development of the world also promotes cultural and 
political pluralism, and brings new challenges to the mainstream ideological education. Under such circumstances, college students' world view, vie of life and value are greatly changing. Western culture and values are silently getting into college students' brain, and the so-called consumption concepts also gradually influence the living style of college students, so that many college students become material, and forget about the values and original intention that they should hold under the mainstream ideology with socialist characteristics. Thus, college students lavish praise on the superiority of western political institutions and especially social form, which reflects that college students' political attitude and value orientation have been changed. On the contrary, collectivism and patriotism are rejected. Thus, the function of ideological education with Marxism as the mainstream is bound to be largely weakened.

\section{Impact of Social Transformation}

China is experiencing a social transformation period, during which both culture and economy are changing. Thus, the mainstream ideological education of college students also is changing, which is mainly reflected by the employment direction and social responsibility assignment of college students in future. College students are confused about their life, and impressionable in respect of value orientation and views and values, standing at the cross road of their life.

That college students are confused is because the economic interests-dominated values of people in the social transformation period have significantly changed. With the all-around infiltration of western individualism and egoism, Chinese people lay more and more stress on economic interests when judging values. Thus, the worship for money gets a chance to step in, sweeping away all walks of life. Particularly, in the existing environment where rule by law is not completely fulfilled, college students' subjective judgment is more likely to be influenced by extreme social phenomenon, and college students are likely to be misled, so that their principles and faiths sway, and their receptivity of mainstream ideological education is directly affected.

\section{Impact of New Media}

New media, as the "fourth media" in the new era, most greatly influences the young generation, in particular college students, and also brings more opportunities and possibilities to college students, which greatly impacts the mainstream ideological education of universities.

Speaking of the impact of new media on mainstream ideology, we cannot ignore the characteristics of new media, namely high information spreading speed, timeliness and large coverage. New media is the most efficient tool of seizing the ideological front. Western countries are good at producing headline-grabbing news via new media to spread their ideas and concepts to Chinese people, which influences the ideas and values of college students, and collapses the national mainstream ideology of college students. According to the surveys mentioned herein, about $65 \%$ students in a university have been completely captured by the material values of western ideology, so that they prefer the valentine's day, the Christmas day, western famous brands, American blockbusters, American fast food, and knowing western culture via the Internet, which increases the difficulty of mainstream ideological education of universities. It is thus clear that the impact of new media on college students' values is great, and should not be ignored ${ }^{[2]}$.

\section{Development Strategy of Mainstream Ideological Education of Universities}

The mainstream ideological education of Chinese universities should be enhanced from network environment, teaching environment, and social environment, so as to achieve a long-term development.

\section{Network Environment}

It is an era of internet culture dominated by virtual practice online, and the cultural environment is self-driven, time sensitive, equal, and open. Under such circumstances, positive advanced culture and 
negative backward culture will conflict with each other. Universities are supposed to make full use of the convenient network environment to facilitate the mainstream ideological education, guide college students to hold correct opinions online, enrich the methods of education and teaching via network platforms, teach students to identify and accept positive healthy contents and avoid and discard false information and fraudulent conduct, offer MOOCs, small class and distance education to popularize ideological and political education and mainstream ideological education, and train students to develop good network culture literacy, aesthetic sentiment, and political tendency, to create a healthy and positive network ethical climate for universities. Besides, the Internet also should be taken advantage of to fight against some network misconduct violating ideology and morality, to form a positive network morality, and prevent improper network behaviors.

\section{Teaching Environment}

Concerning teaching environment, teaching methods and efficiency should be improved to develop the mainstream ideological education. In this paper, it is held that two points should be conformed to.

Firstly, the people-oriented principle should be observed, and the feelings and practice of students should be respected. Serious and rational as the mainstream ideological education is, it is not inflexible, and not divorced from reality and life. Hence, universities should adhere to the students-based principle, give full respect to student for their learning activities and performances, guide them to solve problems from the aspects of psychology, thinking and idea, seek common growth with students, get close to students via ideological and political education, and observe students' learning and life tendency in a dynamic way, to unearth and adjust students' emotional factors, and demonstrate abstract elusive theories via life-based examples. On the other hand, daily classroom teaching should be focused on, supplemented by life education, to help students to realize the profoundness of mainstream ideological education from life. Besides, universities can organize speech contests, poetry recitation, debate competitions to activate students' thoughts and ideas, and make students and teacher become friends who can exchange ideas and feelings.

Secondly, respect for differences should be showed, to make the mainstream ideological education be more inclusive and unified. According to the dialectical materialism of Marxism, the unification of materials and human ideology should be based on the diversity and differences of materials which are based on objective reality. Universities should unify ideologies in mainstream ideological education, earnestly balance the ossification and differentiation of education, and realize rational distribution. Universities should not conquer students' thoughts with compulsory theories, but exert influence on students with profound life principles, to help students understand the connotation of the mainstream ideology, and convince students to accept the education.

\section{Social Environment}

Social environment is outside the campus of universities, including social environment and family environment. Concerning family environment, the most basic living environment of human being, family education should consist with school education, throughout which the mainstream ideology should run, and families should strive to foster students to form good and healthy moral characters and living habits, and give them a good family atmosphere full of cultural deposits, which will make for the promotion of mainstream ideological education of universities, bringing out the best in the education of society, family and school, and achieving a good education effect ${ }^{[3]}$.

The advent of the new era poses unprecedented challenges to the mainstream ideological education of universities, and greatly influences the education of students. Thus, universities should innovate and develop the education styles and forms, give more opportunities to students to experience society, recognize themselves, and stand up to difficulties, promote students to realize their shortcomings in world view, view of life and value in learning process, affect students with all-around education methods from different perspectives, and build a set of viable mainstream ideological education mechanism, to lay a foundation for outputting talents with healthy and perfect personality and comprehensive abilities in future. 


\section{Acknowledgments}

This paper is the phased achievement of the project titled Research on Ideology Safety and Political Value Education of College Students approved in 2015 of the "Twelfth Five-Year" Plan of Shandong science of education program (numbered YBX15001) and the project titled Research on Ideological Ability Building of Leading Cadres in Taian City approved in 2016 of Taian social science program (numbered 16-YB-049).

\section{References}

[1] Ni Jingli. A Study on Problems of Mainstream Ideological Education of College Students in the Network Era. Shandong Normal University, 2013: 26.

[2] Zhang Yunling. Research on Mainstream Ideological Education of Universities from the Perspective of Humanism of Marxism.Shenyang University of Technology, 2016: 19.

[3] Wan Xiangkun. Research on Innovation of Mainstream Ideological Construction of Chinese Universities. The Fourth Military Medical University, 2011: 39. 